\title{
Account of microwave irradiation for accelerating organic reactions
}

\author{
El Sayed H. El Ashry ${ }^{*}$ and Ahmed A. Kassem \\ Chemistry Department, Faculty of Science, Alexandria University, Alexandria, Egypt \\ E-mail: eelashry60@hotmail.com; eelashry60@link.net
}

\begin{abstract}
This account provides a summary of a chapter on Microwave Irradiation for Accelerating Organic Reactions in Advances in Heterocyclic Chemistry, volume 90, Part II: Six, Sevenmembered, Spiro and Fused Heterocycles by E. S. H. El Ashry, A. A. Kassem and E. Ramadan. Microwave irradiation (MWI) has been used extensively in organic synthesis. Application of MWI leads to many advantages, like the use of non-corrosive and inexpensive reagents, in addition to the eco-friendly "green chemistry" economical and environmental impacts.
\end{abstract}

Keywords: Microwave irradiation, green chemistry, organic synthesis, six and seven-membered heterocycles, spiro and fused heterocycles

\section{Table of Contents}

1. Introduction

2. Heterocycles with one heteroatom

3. Heterocycles with two heteroatoms

4. Heterocycles with three heteroatoms

5. Heterocycles with four heteroatoms

6. Spiroheterocycles

\section{Introduction}

A widely used and preferred tool for accelerating organic reactions, microwave irradiation (MWI), has been applied to organic reactions in the absence of solvent and/or in the presence of a solid support, such as clays, alumina and silica, resulting in shorter reaction times and higher product yields than those obtained by using conventional heating. Specialized ovens or reactors have been developed to avoid the risk from domestic MW ovens. The terminologies: microwave for organic reaction enhancement "MORE" and microwave-assisted organic synthesis "MAOS" 
have been proposed. The reactions which are not possible under the conventional conditions, can sometimes be affected by the high energy of MWI. In addition, the use of MWI leads to the higher reaction selectivity and to the utilization of non-corrosive, inexpensive and environmentfriendly catalysts. These aspects have attracted our attention and a chapter on "Microwave Irradiation for Accelerating Organic Reactions" is now in press. Part II: Six, Seven Membered, Spiro and Fused Heterocyclic Ring Systems ${ }^{1}$ following Part I: Three, Four and Five Membered Heterocycles in the former volume ${ }^{2}$. The literature has been organized according to the number of heteroatoms in heterocycles; the fused heterocycles have been located according to the heterocycle that was built under MWI or as a reaction of the heterocycles. Heterocycles having either fused benzene rings or other heterocycles have been located under a separate title if sufficient literature is available. Since the number of references is very high, the references provided herein are the most recent ones for each class of compound and/or heterocycle.

\section{Heterocycles with one heteroatom}

This part includes heterocycles with one oxygen, sulfur or nitrogen as heteroatoms. Hetero DielsAlder reactions of glyoxylates with pentadienes were accelerated under MWI to afford a mixture of cis and trans pyrans; degradation as well as polymerization were avoided ${ }^{3}$. Several homoallyl alcohols were reacted with aldehydes to give tetrahydropyrans. Tetrahydropyranylation of alcohols by DMF has been conducted by using silica gel as a support, and the selective cleavage was done using 4-aza-1-benzyl azoniabicyclo[2.2.2] octane dichromate. Reaction of 2- and 2,4dihydroxybenzaldehydes and 2,2-dimethyl-7-chromanols with 3-methyl-2-butenal gave the corresponding chromene 4 . Naphthopyrans or propargyloxynaphthopyrans were obtained from propargyl or bispropargyl naphthyl ethers. Reaction of salicylaldehydes with enamines gave isoflav-3-enes. Intramolecular Diels-Alder cycloadditions were used for the synthesis of 1-3. A one-pot diastereoselective synthesis of pyranothiazoles 4 was achieved ${ }^{5}$.

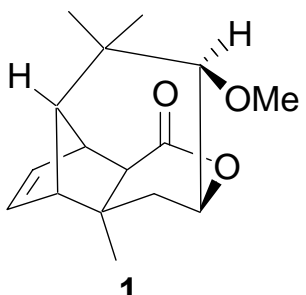

1

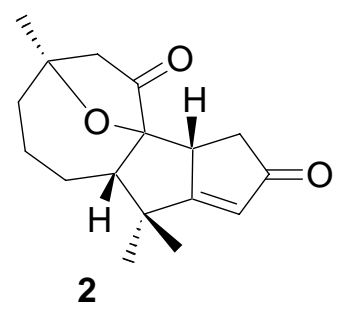

2

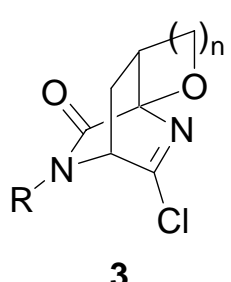

3

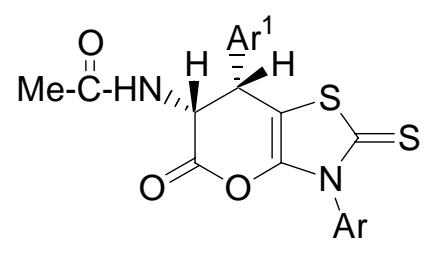

4

Reaction of 5,5-dimethyl-1,3-cyclohexanedione and arylidenemalononitrile gave 5, and of 1,3-diarylthiobarbituric acids with hippuric acid and triethyl orthoacetate or triethyl orthoformate and malononitrile or alkylnitriles gave pyranopyrimidines ${ }^{6} 6$ or 7. Pyranopyrimidines 8 were obtained from reaction of arylidenemalononitriles or $\mathrm{N}$-phenyl maleimides with barbituric $\operatorname{acid}^{7,8}$. 
<smiles>[R]C1C(C#N)=C(N)OC2=C1C(=O)CC(C)(C)C2</smiles>

5

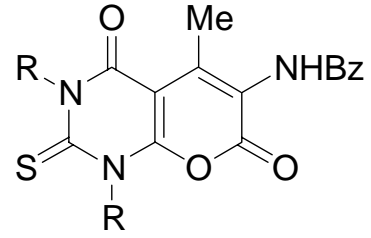

6

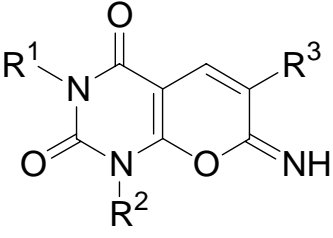

7<smiles>[R]C1=C(N)Oc2[nH]c(=O)[nH]c(=O)c2C1C#N</smiles>

8

Chemoselective intramolecular domino Knoevenagel hetero Diels-Alder reaction of 4hydroxy-1,2-dihydro-2-quinolinones with 2-(3-methyl-2-butenyloxy)benzaldehyde gave the angular and linear pyranoquinolinones ${ }^{9}$. The corresponding chromanones 9 have been obtained by the reaction of 3 -hydroxy phenolic derivatives with $N$-cinnamoylazoles ${ }^{10}$. Coumarins were synthesized by condensation of salicylaldehydes with malonic acid, derivatives of ethyl acetate or hydrazides and by Knoevenagel condensation of benzaldehydes or acetophenones with Meldrum's acid; reactions did not take place in the absence of MWI or catalyst ${ }^{11,12}$. Diels-Alder reaction of (E)- and (Z)-3-styrylchromones with $N$-methyl and $N$-phenyl maleimide afforded the respective exo- and endo-cycloadducts stereoselectivly. Lawesson's reagent converted flavones and isoflavones into their thio analogs ${ }^{13}$. Reaction of arylidenemalononitriles with $\alpha$-methylene ketones gave 2-amino-3-cyanopyridines ${ }^{14}$ 10. The reactions between enaminocarbonyl compounds and 4-ylidene-2-phenyloxazol-5-(4H)-ones or cyanomethylene or nitromethane gave pyridine derivatives 10. Bis-pyridylamides were prepared by direct nucleophilic substitution reactions. Pyridylthioglycosides $\mathbf{1 1}$ were obtained from 2-chloropyridines and glycosyl isothiouronium salts ${ }^{15}$. $\mathrm{N}$-methylation using formic acid-formaldehyde mixtures was used to prepare a number of piperidine derivatives. Michael addition of $2(1 \mathrm{H})$-pyridones to dimethylacetylenedicarboxylate (DMAD) afforded $12^{16}$.

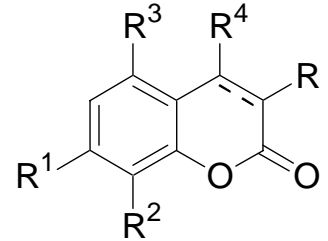

9

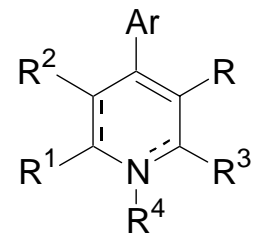

10

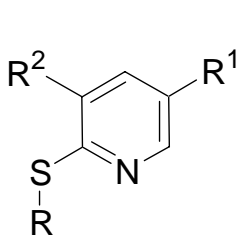

11

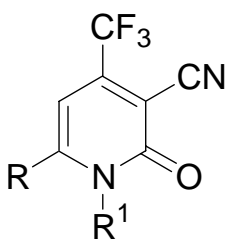

12

Reaction of $N, N$-dimethylformamide dimethyl acetal with 2,6-diacetylpyridine gave 2,6bis(3-dimethylamino-1-oxoprop-2-enyl)pyridine ${ }^{17}$. Synthesis of tris(2,2'-bipyridine)ruthenium (II) perchlorate trihydrate has been achieved ${ }^{18}$. Benzimidazoles with pyridyl substituents and 7,7'-bis-indolizines were prepared ${ }^{19}$. Intramolecular Diels-Alder reaction of indolizidine with 2cyano-substituted $N$-alkyl azadiene was done. Reaction of pyridinium $N$-dicyanomethylide with ethyl phenylpropiolate or phenylacetylene gave the possible regioisomers $13^{20}$. Reaction of 4chloroazines with benzotriazoles gave the triazole derivatives 14, and 2-amino-pyridines with 2naphthaldehyde or pyridine-2-aldehyde and isocyanide afforded the imidazo[1,2-a]pyridines $15^{21,22}$. Oxazolopyridines 16 were obtained by intramolecular cyclization of hydroxyamidines ${ }^{23}$. 
<smiles>[R]c1c([R])c2cccc([R])n2c1[R]</smiles>

13<smiles>[R]c1cc(-n2nnc3cc([R])c([R])cc32)ccn1</smiles>

14<smiles>[R]Nc1c([R])nc2ccc([R])cn12</smiles>

15<smiles>[R]c1nc2ncccc2o1</smiles>

16

Cycloaddition between electron rich 6-[(dimethylamino)methylene]amino-1,3-dimethyl uracil and various electron deficient substrates gave pyrido[2,3-d]pyrimidine derivatives in a high regiospecific manner. The pyrido[2,3-d]pyrimidinones 17 and their N-oxides 18, 5-deaza5,8-dihydropterins 19 and pyrido[2,3-d]pyrimidinone 20 were synthesized from 6-aminouracils, 6-hydroxyaminouracils, 2,6-diaminopyrimidin-4-one and 6-amino-1,3-dimethyl-5-formyluracil, respectively ${ }^{24,25}$.<smiles>[R]c1cc2c(=O)n([R])c(=O)n([R])c2nc1N</smiles>

17<smiles>[R]c1cc2c(=O)n([R])c(=O)n([R])c2[n+]([O-])c1N</smiles>

18<smiles>[R]C1=C([R])C([R])c2c(nc(N)[nH]c2=O)N1</smiles>

19
20

Pyrazolo[3,4-b]pyridines, the 7-chloro-6-fluoro-2,4-dimethylquinoline and its mercaptothiadiazolyl or oxadiazolyl quinolines 21 were prepared via Diels-Alder reaction conversion of methyl 2-(3-oxo-3-phenylpropenylamino)benzoate into 3-benzoyl-1H-quinolin-4-one $22^{26,27}$. A mixture of aniline derivatives and malonic ester gave a variety of 3-aryl-4-hydroxyquinolin2(1H)-ones 23. Condensation of isatins with ketones afforded quinoline-4-carboxylic acids. 2Aryl-1,2,3,4-tetrahydro-4-quinolinones 22 and carbazolylquinolone were also prepared. The substitution of 2-chloroquinoline gave the 2-substituted quinolines. Basic alumina has catalyzed the $\mathrm{C}-\mathrm{C}$ bond formation between 2-hydroxy-1,4-naphthoquinone and 2-chloroquinoline derivative to give 21. Reaction of organic halides with 8-hydroxyquinolines gave the respective ethers. The azodye derivatives of $\mathbf{2 1}$ were prepared in the absence of solvent. Silica gel catalyzed the formation of 2-ketomethylquinolines from reaction of 2-methylquinolines with acyl chlorides.<smiles>[R]c1cc2nc([R4])c([R])c([R])c2cc1[R]</smiles>

21<smiles>[R]c1c([Al])[nH]c2ccccc2c1=O</smiles>

22<smiles>[R][R]1C=Cc2c(ccc([R])c2O)N([R])C1=O</smiles>

23<smiles>CC1(C)CC(=O)C2=C(C1)NC(=O)CC2Br</smiles>

24 
The octahydroquinolines 24 and decahydroacridines were obtained from dimedone ${ }^{28}$. On montmorillonite KSF clay, acridine derivatives 25 were obtained. Reaction of arylidenemalononitriles with cyclic ketones gave 2-amino-3-cyanopyridines ${ }^{14} \mathbf{2 6}$. Reaction of diphenylamine and dicarboxylic acids or arylacetic acids was catalyzed by zinc chloride to give acridines. Pyrimido[4,5-b]quinolines 27 were synthesized ${ }^{29}$.

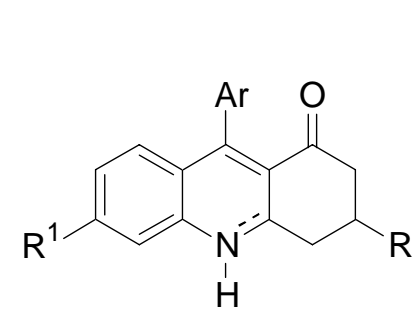

25

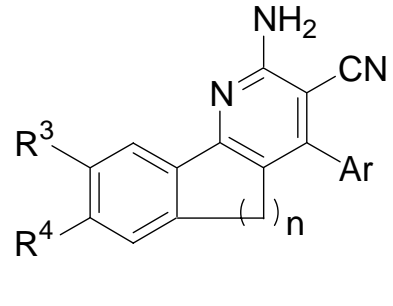

26<smiles>CN1c2ccccc2C([Al])c2c1n([Al])c(=S)n([Al])c2=O</smiles>

27

$\beta$-Lactams 28 were obtained from reaction of acylhydrazones with chloroacetyl chloride ${ }^{30}$. $N$-Alkylation of acridine derivatives with 1,3-propane sultone gave 29. $\beta$-Phenethylamides gave 3,4-dihydroisoquinolines and $\mathrm{N}$-sulfonyl gave isoquinolines 30. Nucleophilic substitution of 4bromoisoquinoline gave the corresponding 4-substituted isoquinolines. $O$-Bromobenzaldehyde was reacted with allylamine and then homophthalic anhydride to afford $31^{11}$.<smiles>[R][R]C(C)=O</smiles>

28<smiles>[R]c1ccc2cc3ccc([TlH])cc3[n+](CCCS(=O)(=O)O)c2c1</smiles>

$29 \mathrm{R}^{1}=\mathrm{H}, \mathrm{NM}_{2}$<smiles>[R]C(=O)c1nccc2cc([R])c([R])cc12</smiles>

30<smiles>C=CCN1C(=O)c2ccccc2[C@H](C(=O)O)C1c1ccccc1Br</smiles>

31

Aza-Wittig reaction in 3-(o-azidophenyl)-1-methyl-1H-quinolin-2-one gave the alkaloid cryptotackieine and cyclization of hydroxyamidines gave the oxazoloquinolines. Condensations of 1-cyanomethylene tetrahydroisoquinoline with $\beta$-unsaturated aldehydes afforded 6,7-dihydro$4 H$-benzo[a]quinolizines. Tetrahydroindolizinediones were reacted with 2 -aminobenzaldehydes to give $32^{31}$. Pyrazoloquinolines 33 were synthesized from $\beta$-chlorovinylaldehydes and pyrazolylanilines $^{32,33}$. 2-Arylidenehydrazino-4-methylquinolines were cyclized to give 34 . Condensation of 2-hydrazino-4-methylquinoline with aromatic ketones under MWI gave hydrazones whereas its reaction with $\mathrm{POCl}_{3}$ in $\mathrm{DMF}$ gave $35^{34}$. The polycyclic quinolines 37-39 have been prepared. 
<smiles>[R]c1cc2cc3c(nc2cc1[R])-c1cc(C)c([R])c(=O)n1C3</smiles>

32<smiles>CCC(=O)c1cc2n(c(=O)c1C)Cc1cc3ccccc3nc1-2</smiles>

37<smiles>[R]c1ccc2nc3c(c([R])nn3[R])c([R])c2c1</smiles>

33<smiles>Cc1cc2nnc([Al])n2c2ccccc12</smiles><smiles>Cc1cc(-n2cc(C=O)c(Br)n2)nc2ccccc12</smiles>

35<smiles>[R]c1ccc2c(c1)-c1nc3ccccc3c([R])c1CO2</smiles>

\section{Heterocycles with two heteroatoms}

Condensation of anthranilic acid with various ortho-esters and reaction of semicarbazides, gave 2-substituted benzoxazin-4-ones and also by the reaction of hydrazones with aryl-/alkylureas and by salicylaldehyde or 2-hydroxyacetophenones with 4-aryl-/alkyl-semicarbazides. Hydrolysis of $o$-aminoesters and subsequent treatment with phosgene gave 40. Fused oxazine with bridge head nitrogen $\mathbf{4 1}$ and triazolo[3,4-b]thiazines $\mathbf{4 2}$ were also prepared ${ }^{35,36,37}$. The 2,3dihydrobenzoxazine $\mathbf{4 3}$, thiomorpholines $\mathbf{4 4}$ and phenothiazines $\mathbf{4 5}$ were prepared ${ }^{38}$.<smiles>O=c1[nH]c2sccc2c(=O)o1</smiles>

40<smiles>CC(C)(C)OC(=O)N1CCOc2ccccc21</smiles>

43<smiles>CC12CCC(=O)N1CCCO2</smiles>

41<smiles>OC1CSc2nnc(Br)n2C1</smiles>

42<smiles>[Al]N1CCOCC1</smiles>

44<smiles>[R]c1ccc2c(c1)Nc1ccccc1S2</smiles>

45

Reaction of hydrazides with chloroacetic acid, dichloroacetic acid and chloroacetyl chloride afforded the pyridazinediones ${ }^{39} \mathbf{4 6}$ and 47 . Glyoxal monophenylhydrazone was reacted with methyl acetoacetate to give the corresponding pyridazinone ${ }^{40} \mathbf{4 8}$. 
<smiles></smiles>

46<smiles>[R16]SC1CC(=O)NNC1=O</smiles>

47<smiles>[R]c1cnn([R])c(=O)c1[R]</smiles>

48

Reaction of alkynones with either benzamidine, acetamidine or guanidine hydrochloride gave pyrimidines 49, and chalcones with urea gave $\mathbf{5 0}^{41}$. The Biginelli products have been formed by irradiation of $\beta$-ketoester, aryl aldehyde, (thio)urea derivatives and PPE or a mixture of thiourea, ethyl acetoacetate and aldehydes. Pyrimidyl halides underwent nucleophilic substitutions with thiolate or alkoxy ions. Iodination of pyrimidinones and their nucleosides gave $\mathbf{5 1} \mathbf{1}^{42}$. The hydroxymethylation of pyrimidinones was carried out by using paraformaldehyde to give 5-hydroxymethyl derivatives 52. Coupling of organozinc reagent with 2,4dichloropyrimidine gave pyridyl-pyrimidines. Condensation of aromatic aldehydes with thiobarbituric acid gave 5-arylidenethiobarbituric acids. Reaction of barbituric acid with aldehydes gave 5-(arylmethylene)-2,4,6-(1H,3H,5H)pyrimidinetriones ${ }^{43}$. Anthranilonitrile was reacted with aromatic nitriles to afford the corresponding 4-aminoquinazolines ${ }^{44}$.

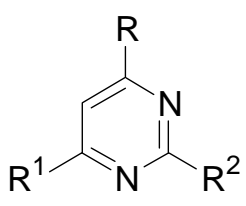

49<smiles>[X]C1=NC(=[X])C([R])=C([R])N1[R]</smiles>

50<smiles>[X]c1nc(=O)c(I)c([R])[nH]1</smiles>

51<smiles>[R]c1cn([R])c(=O)[nH]c1=O</smiles>

52

Aryl mercuric chloride was reacted with barbituric acid or thiobarbituric acid derivatives to afford mercuric compound $53^{45}$. Michael addition of a chalcone to thiobarbituric acid and subsequent cyclization gave pyrano[2,3-d]pyrimidines 54. Quinazolin-4(3H)-ones 55 were prepared from anthranilic acid, formic acid and an amine. Condensation of isatoic anhydride, amines and ortho-esters gave quinazolines ${ }^{46} \mathbf{5 6 .}$

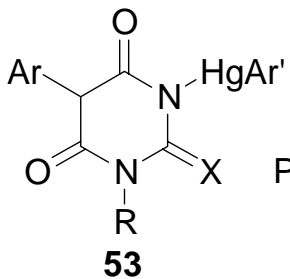

53<smiles>[R]n1c2c(c(=O)n([R])c1=S)C([CH])(c1ccccc1)C=C([InH])O2</smiles>

54<smiles>[R]c1nc2ccccc2c(=O)n1[R]</smiles>

55<smiles>[R]c1nc(N)c2ccccc2n1</smiles>

56

Thionation of quinazolinones and then reaction with anthranilic acid derivatives gave $57^{47}$. A regioselective reaction of isatoic anhydride with isatin-3-imines gave $\mathbf{5 8}^{48}$. Selfpolymerization of isatoic anhydride, doped over montmorillonite yielded 
dibenzo[3,4:7,8][1,5]diazocinodiquinazolin-10,21-dione. Syntheses of indolo[1,2-c]quinazolines and benzimidazo[1,2-c]quinazolines ${ }^{49} 59$ and $\mathbf{6 0}$.<smiles>[R]c1cc2nc3c4cc([R])c([R])cc4ncn3c(=O)c2cc1[R]</smiles>

57

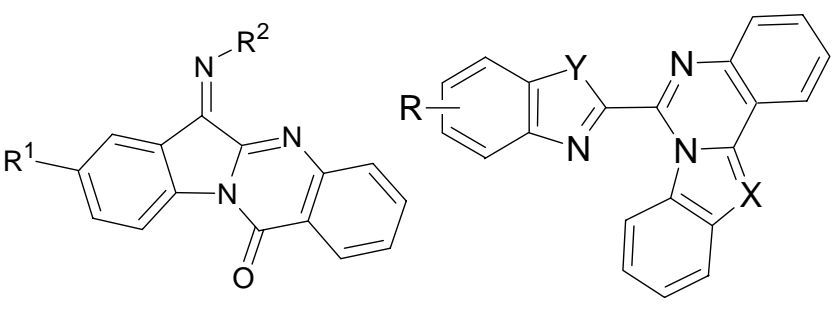

58
$59 \quad \mathrm{Y}=\mathrm{CH}, \mathrm{N}$ $\mathrm{X}=\mathrm{S}, \mathrm{O}$

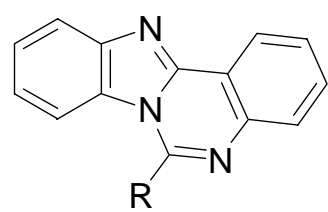

60

Reaction of indoloquinazoline and anthranilic acids, adsorbed on graphite, led to $\mathbf{6 1}^{50}$. Reaction of aldehydes, 2-aminopyrimidine and alkyl isocyanide afforded 62 . A route to 63 was described by reaction of $N$-acyl imidates with imidazolidine ketene aminals ${ }^{51}$.

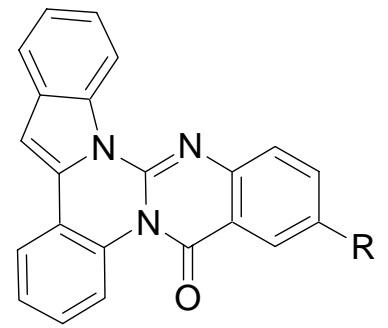

61<smiles>[R]Nc1c([R])nc2ncccn12</smiles>

62<smiles>[R]C1=NC([R])=C([X])C2=NCCN12</smiles>

63

A number of heterocycles with bridged head nitrogen such as pyrazolo[1,5-a]pyrimidines 64, triazolo[1,5-a]pyrimidines 65, pyrimido[1,2-a]benzimidazole 66 and pyrimido-pyrazolo[3,4b]pyridines 67 have been prepared ${ }^{52}$.<smiles>[R]c1ccnc2cc(-c3ccccc3)nn12</smiles>

64<smiles>[R]c1ccnc2ncnn12</smiles>

65<smiles>CCc1ccn2c(n1)nc1ccccc12</smiles>

66<smiles>[R]c1cc([R])c2c(n1)nn1c(C(F)(F)F)c([R])cnc21</smiles>

67

The imidazo[1,5-a]pyrimidines $\mathbf{6 8}$ and benzo[4,5]imidazo[1,2-a]pyrimidines $\mathbf{6 9}$ were prepared. Cyclization of imidazolones with thiourea or cyanoguanidine gave the cis and trans isomers of 70. Xanthine bases, caffeine, theophyline gave the 6-thio and 2,6-dithio derivatives by using Lawesson's reagent ${ }^{53}$. 
<smiles>[R]OC(=O)C1=C(C)Nc2c(OC(N)=O)ncn2C1[Al]</smiles>

68

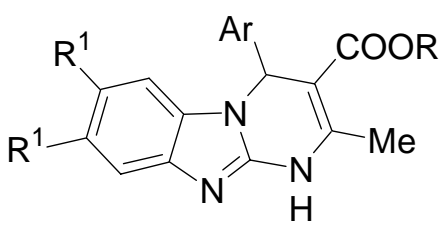

69

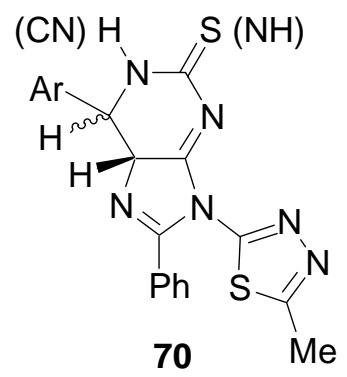

Reactions with diethyl(ethoxymethylene)malonate or 3-formylchromone gave pyrimidine derivatives $\mathbf{7 1}$ or $\mathbf{7 2}$, respectively ${ }^{54}$.<smiles>CCOC(=O)C1=C(Br)N2C=C([Al])C=NC2=NC1c1ccccc1</smiles>

71<smiles>CCOC(=O)C1=CNC2=NC(c3ccccc3)=C(C(=O)OCC)C(C)(Br)N2C1=O</smiles>

72

Heating the diethanolamine or bis(2-chloroethyl)amine hydrochlorides with aniline derivatives gave 1-arylpiperazine derivatives. The 1-substituted piperazines were deuteromethylated. 1,4-Dithiocarbonyl piperazine was obtained from reaction of benzaldehyde with piperazine and sulfur. 1,4-Diacetylpiperazine-2,5-dione were reacted with aldehydes to give the monoarylidene products and then 73. 4-Benzylpiperazine-2,5-dione was reacted with bromobenzene to give 74. Diels-Alder cycloaddition of pyrazinone with ethene gave $75^{55,56}$.

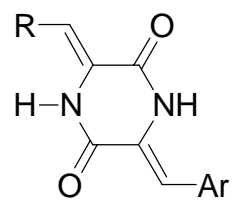

73

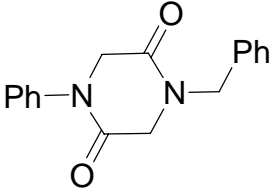

74

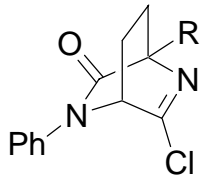

75

Condensation of o-phenylenediamine with methylglyoxal, aldohexoses and aryl or alkyl acyloins gave the corresponding quinoxalines ${ }^{57}$ 76. Indoloquinoxalines were obtained from isatin. Carbethoxymethylation of isatin and then reaction with $o$-phenylenedimine gave the respective indoloquinoxalines $\mathbf{7 7}$, whereas hydrazide was condensed with aromatic aldehydes and monosaccharides. L-Ascorbic acid or D-isoascorbic acid were oxidized with iodine and then reacted with $\boldsymbol{o}$-phenylenediamine and phenylhydrazine to give quinoxalinones $\mathbf{7 8}$, which were cyclized to pyrazolyl-quinazolinones ${ }^{58,59}$. 
<smiles>[R]c1cc2nc([R])c([R])nc2cc1[Hg]</smiles>

76

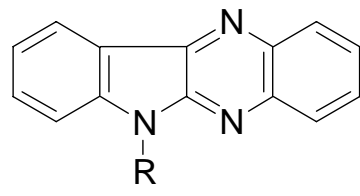

77<smiles>[R]c1ccc2nc([R])c(=O)[nH]c2c1</smiles>

78

Coupling of 4-fluoro-3-nitrobenzoic acid with polyethylene glycol (PEG) which can be converted to the polymer bound 1,2,3,4-tetrahydroquinoxalin-2-one. Cyclocondensation of oxalic acid or diethyloxalate with o-phenylenediamine gave quinoxaline-2,3-dione. Glycosyl isothiouronium salts were coupled with 2-chloroquinoxalines to give the respective thioglycosides. 2,3-Dichloroquinoxaline was converted to quinoxaline-2,3-dithione which upon reaction with acetobromoglucose or 2-amino-2-deoxy-2,3,4,6-tetra-O-acetyl $\alpha$-D-glucopyranosyl chloride gave the corresponding thioglycosides.

Reaction of alloxan monohydrate with 1,2-diaminobenzene or 1,2-diamino-4,5dimethylbenzene gave isoalloxazine and lumichrome $\mathbf{7 9}^{60}$. Dehydrative cyclization of L-threo and D-erythro-glycosyl quinoxalines with aq. $\mathrm{NaOH}$ gave the respective flavazoles, which degraded to $\mathbf{8 0}^{59}$. A mixture of aldehydes, 2-aminopyrazine and isocyanide afforded $\mathbf{8 1}$. Cyclization of pyrido[3,4-b]indoles afforded 82.<smiles></smiles>

$79 \mathrm{R}=\mathrm{H}, \mathrm{Me}$<smiles>ClCc1nn(-c2ccccc2)c2nc3ccccc3nc12</smiles>

80<smiles>[R]Nc1c([R])nc2cnccn12</smiles>

81<smiles>[R][C@]1([2H])NC(=O)[C@@H]2Cc3c([nH]c4ccccc34)CN2C1=O</smiles>

82

The ketene $O, O$-acetals 83 were prepared from the corresponding bromo derivatives by reaction with strong base ${ }^{61}$. A diastereoselective synthesis of the trans- and cis $\mathbf{8 4}$ was carried out. Condensation of substituted aminothiophenols and 2-arylidene-1-tetralone afforded 1,4thiazepines 85. Condensation of $o$-phenylenediamines with $\beta$-ketoesters or 1,1,1-trifluoromethyl3-(isobutoxymethylene)-2-propanones gave $\mathbf{8 4}{ }^{62}$.

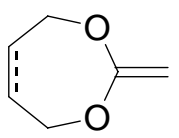

83<smiles>[R]c1cc([X])c(NC(=O)C([R])C([Al])[AlH2])cc1[R]</smiles>

84<smiles></smiles>

85

Pyrrolo[2,1-c][1,4]benzodiazepine-2,5,11-trione was heated with $\mathrm{POCl}_{3}$ to give 2,5dichlorocyclopenta $[b][1,4]$ benzodiazepine as a major product and its lactam as minor product. 
Reaction of 5-substituted isatoic anhydride with allylamines gave 2-amino-5-substituted- $N$-alkyl$N$-(2-propenyl)benzamides which were subjected to diazotization followed by subsequent nucleophilic substitution and cyclization to give 2-methyl-1,4-benzodiazepin-5-ones. A noncovalent DNA-binding agent like pyrrolo[2,1-c][1,4]benzodiazepine-5,11-dione has been synthesized.

\section{Heterocycles with three heteroatoms}

1,2,4-Triazolo[3,4-b][1,3,4]thiadiazoles 86, triazolothiadiazines $\mathbf{8 7}, \mathbf{8 8}$, and $\mathbf{8 9}$ were obtained from 4-amino-5-substituted-4H-1,2,4-triazole-3-thiols ${ }^{63}$.<smiles>[R]c1nn2c([R])nnc2s1</smiles>

86

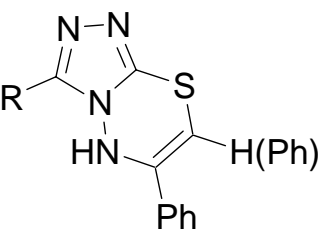

87<smiles>[R]c1nnc2n1NC(=O)CS2</smiles>

88<smiles>[R]c1nnc2n1NC1=C(S2)C(=O)CC(C)(C)C1</smiles>

89

Reaction of aromatic or heterocyclic amines with formaldehyde and urea or phenylthioureas gave 2-(oxo)thioxohexahydro-1,3,5-triazines 90. Regioselective cyclization and isomerization of propargylthio-1,2,4-triazinones were achieved to give the fused heterocycles 9193. Cyclization of isatin 3-thiosemicarbazones gave 94 which can be alkylated to $95^{64}$. The imidazotriazepines 96 were obtained from heating a mixture of hydrazide and ortho-ester.<smiles>[R]C1=NCN([R])CN1[R]</smiles>

90

91<smiles>Cc1nnc(=O)n2c(C)csc12</smiles>

92<smiles>CC1=CSC2=NNC3C=CC=CC3N12</smiles><smiles>[R]c1ccc2[nH]c3nc(=S)[nH]nc3c2c1</smiles>

94<smiles>[R][R17]c1nnc2c3cc([R])ccc3n([R])c2n1</smiles>

95<smiles>[R]C1=NNC(=O)c2[nH]cnc2N1</smiles>

96 


\section{Heterocycles with four heteroatoms}

Hetero-Diels-Alder reactions of chiral 1-aryl-1,2-diaza-1,3-butadienes gave $\mathbf{9 7}^{65}$. Condensation of hydrazones with 2-hydrazino-4-methyl quinoline afforded $\mathbf{9 8}^{39}$.

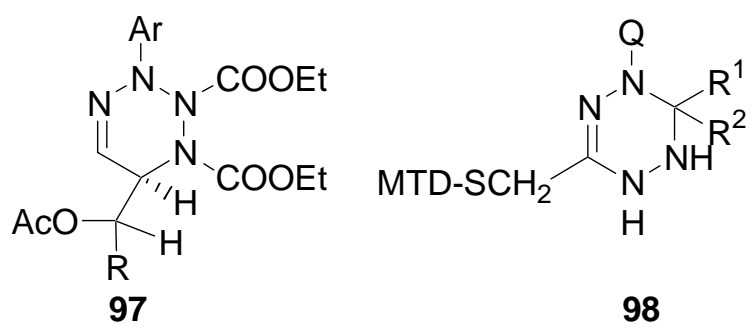

\section{Spiroheterocycles}

A mixture of Meldrum's acid or barbituric acid derivatives, urea and aldehyde gave 99, stereoselectively. Reaction of 2-methylene indoline derivatives with 1-nitroso-2-naphthol gave 100. Spiroheterocycles 101 were prepared from a mixture of isatin and aromatic or heterocyclic $\operatorname{amines}^{66,67,68}$.

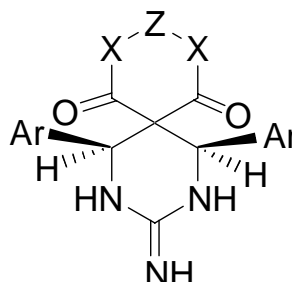

$99 \mathrm{X}=\mathrm{O}, \mathrm{Z}=\mathrm{CMe}$

$X=\mathrm{NH}$ or NMe, $Z=\mathrm{CO}$

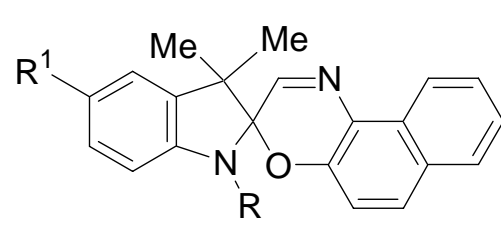

100

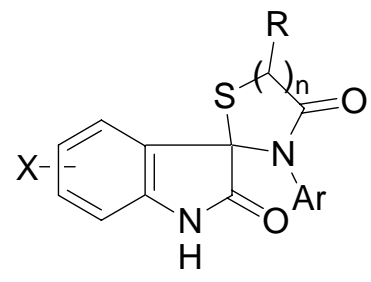

101

\section{References}

1. El Ashry, E. S. H.; Ramadan, E.; Kassem, A. A.; Hagar, M. Adv. Heterocycl. Chem. 2005, 88, 1 and references cited therein.

2. El Ashry, E. S. H.; Kassem, A. A.; Ramadan, E. Adv. Heterocycl. Chem. 2005, 90, in press, and references cited therein.

3. Stambouli, A.; Chastrette, M.; Soufiaoui, M. Tetrahedron Lett.1991, 32, 1723.

4. Hajipour, A. R.; Mallakpour, S. E.; Mohammadpoor-Baltork, I.; Khoee, S. Synth. Commun. 2002, 32, 611 .

5. Moghaddam, F. M.; Sharifi, A.; Saidi, M. R. J. Chem. Res. (S) 1996, 338.

6. Tu, S. -J.; Gao, Y.; Guo, C.; Shi, D. -Q.; Lu, Z. -S. Synth. Commun., 2002, 32, 2137. 
7. Gao, Y.; Tu, S.; Li, T.; Zhang, X.; Zhu, S.; Fang, F.; Shi, D. Synth. Commun., 2004, 34, 1295.

8. Devi, I.; Borah, H. N.; Bhuyan, P. J. Tetrahedron Lett., 2004, 45, 2405.

9. Manikandan, S.; Shanmugasundaram, M.; Raghunathan, R. Tetrahedron, 2002, $58,8957$.

10. Barbry, D.; Champagne, P. J. Chem. Res. (S), 2001, 78.

11. Bose, A. K.; Manhas, M. S.; Ganguly, S. N.; Sharma, A. H.; Banik, B. K. Synthesis, 2002, 1578 .

12. Bogdal, D. J. Chem. Res. (S), 1998, 468.

13. Pinto, D. C. G. A.; Silva, A. M. S.; Almeida, L. M. P. M.; Carrillo, J. R.; Diaz-Ortiz, A.; de la Hoz, A.; Cavaleiro, J. A. S. Synlett., 2003, 1415.

14. Paul, S.; Gupta, R.; Loupy, A. J. Chem. Res. (S), 1998, 330.

15. El Ashry, E. S. H.; Awad, L.; Abdel Hamid H.; Atta, I. A. unpublished results, 2005.

16. Krishnaiah, A.; Narsaiah, B. J. Fluorine Chem., 2002, 113, 133.

17. Pleier, A. K.; Glas, H.; Grosche, M.; Sirsch, P.; Thiel, W. R. Synthesis, 2001, 55.

18. Matumura-Inoue, T.; Tanabe, M.; Minami, T.; Ohashi, T. Chem. Lett., 1994, 2443.

19. Dinica, R. M. ; Druta, I. I.; Pettinari, C. Synlett., 2000, 1013.

20. Diaz-Ortiz, A.; Diez-Barra, E.; de la Hoz, A.; Loupy, A.; Petit, A.; Sanchez, L. Heterocycles, 1994, 38, 785.

21. Molina, A.; Vaquero, J. J.; Garcia-Navio, J. L.; Alvarez-Builla, J. Tetrahedron Lett., 1993, 34, 2673.

22. Ireland, S. M.; Tye, H.; Whittaker, M. Tetrahedron Lett., 2003, 4369.

23. Granier, E.; Blanchard, S.; Rodriguez, I.; Jarry, C.; Leger, J. M.; Caubere, P.; Guillaumet, G. Synthesis, 2003, 2033.

24. Bagley, M. C.; Singh, N. Synlett, 2002, 1718.

25. Devi, I.; Bhuyan, P. Synlett, 2004, 283.

26. Kidwai, M.; Bhushan, K. R.; Sapra, P.; Saxenab, R. K.; Gupta, R. Bioorg. \& Med. Chem., 2000, 8, 69.

27. Almazroa, S.; Elnagdi, M. H.; Salah, A. M. J. Heterocycl. Chem., 2004, 41, 1.

28. Tu, S. J.; Lu, Z.; Shi, D.; Yao, C.; Gao, Y.; Guo, C. Synth. Commun., 2002, 32, 2181.

29. Ahluwalia, V. K.; Goyal, B.; Das, U. J. Chem. Res. (S), 1997, 266.

30. Kidwai, M.; Sapra, P.; Buhshan, K. R.; Saxena, R. K.; Gupta, R.; Singh, M. Monatsh. Chem., 2000, 85.

31. Perzyna, A.; Houssin, R.; Barbry, D.; Henichart, J. P. Synlett, 2002, 2077.

32. Rajendran, S. P.; Manonmani, M.; Vijayalakshni, S. Org. Prep. Proc. Int., 1994, $26,383$.

33. Danel, A.; Chaczatrian, K.; Tomasik, P. Arkivoc, 2000, 1, 51.

34. Kidwai, M.; Goel, Y.; Kumar, R. Indian J. Chem., Sect. B 1998, 37B, 174.

35. Pilard, J. F.; Klein, B.; Texier-Boullet, F.; Hamelin, J. Synlett, 1992, 219.

36. El Ashry, E. S. H.; Kassem, A. A.; Abdel Hamid, H.; Louis, F. F.; Kattab, Sh. A. N. Aouad, M. R. unpublished results (2005). 
37. Ashry, E. S. H. El; Rashed, N.; Ramadan, E.; Abdel-Mageed, S. M.; Rezki, N. unpublished results (2005).

38. Buon, C.; Chacun-Lefevre, L.; Rabot, R.; Bouyssou, P; Coudert, G. Tetrahedron, 2000, 56, 605.

39. Kidwai, M.; Kumar, R. Gazz. Chim. Ital., 1997, 127, 263.

40. Jolivet, S.; Toupet, L.; Texier-Boullet, F.; Hamelin, J. Tetrahedron, 1996, 52, 5819.

41. Bagley, M. C.; Hughes, D. D.; Taylor, P. H. Synlett, 2003, 259.

42. Paolini, L.; Petricci, E.; Corelli, F.; Botta, M. Synthesis, 2003, 1039.

43. Villemin, D.; Labiad, B. Synth. Commun., 1990, 20, 3333.

44. Seijas, J. A.; Vazquez-Tato, M. P.; Martinez, M. M. Tetrahedron Lett., 2000, 41, 2215.

45. Kidwai, M.; Misra, P.; Bhushan, K. R. Polyhedron, 1999, 18, 2641.

46. Dabiri, M.; Salehi, P.; Khajavi, M. S.; Mohammadi, A. A. Heterocycles, 2004, 63, 1417.

47. Alexandre, F. R.; Berecibar, A.; Wriggleswortha, R.; Bessonb, T. Tetrahedron, 2003, 59, 1413.

48. Azizian, J.; Mohammadi, A. A.; Ardakani, F.; Karimi, A. R.; Mohammadizadeh, M. R. Heterocycles, 2004, 63, 791.

49. Pessoa-Mahana, H.; Pessoa-Mahana, C. D.; Salazar, R.; Valderrama, J. A.; Saez, E. ArayaMaturana, R. Synthesis, 2004, 436.

50. Domon, L.; Le Coeur,C.; Grelard, A.; Thiery, V.; Bessona, T. Tetrahedron Lett., 2001, 42, 6671.

51. Rahmouni, M.; Derdour, A.; Bazureau, J. P.; Hamelin, J. Synth. Commun., 1996, $26,453$.

52. Al-Shiekh, M. A.; Salah El-Din, A. M.; Hafez, E. A.; Elnagdi, M. H. J. Chem. Res. (S), 2004 , 174 .

53. Rico-Gomez, R.; Najera, F.; Lopez-Romero, J. M.; Canada-Runder, P. Heterocycles, 2000, 53, 2275.

54. Eynde, J. J. V.; Hecq, N.; Kataeva, O.; Kappe, C. O. Tetrahedron, 2001, 57, 1785.

55. Villemin, D.; Ben Alloum, A. Synth. Commun., 1990, 20, 3325.

56. Van der Eycken, E.; Appukkuttan, P.; De Borggraeve, W.; Dehaen, W.; Dallinger, D.; Kappe, C. O. J. Org. Chem., 2002, 67, 7904.

57. Goswami, S.; Adak, A. K. Tetrahedron Lett., 2002, 43, 8371.

58. El Ashry, E. S. H.; Ramadan, E.; Abdel Hamid, H.; Hagar, M. J. Chem. Res. (S), 2005, 299.

59. El Ashry, E. S. H.; Atta, K. F.; Aboul-Ela, S.; Abd-Meksoud, H. H.; Beldi, R. unpublished results (2005).

60. Villemin, D.; Martin, B. Synth. Commun., 1995, 25, 2319.

61. Diaz-Ortiz, A.; Prieto, P.; Loupy, A.; Abenhaim, D. Tetrahedron Lett., 1996, 37, 1695.

62. Bougrin, K.; Bennani, A. K.; Tetouani, S. F.; Soufiaoui, M. Tetrahedron Lett., 1994, 35, 8373.

63. Kidwai, M.; Goel, Y.; Kumar, P.; Kumar, K. Indian J. Chem., Sect.B 1997, 36B, 782.

64. Dandia, A.; Arya, K.; Sati, M. Synth. Commun., 2004, 34, 1141. 
65. Avalos, M.; Babiano, R.; Cintas, P.; Clemente, F. R.; Jimenez, J. L.; Palacios, J. C. Sanchez, J. B. J. Org. Chem., 1999, 64, 6297.

66. Dandia, A.; Upreti, M.; Rani, B.; Pant, U. C. J. Chem. Res. (S), 1998, 752.

67. Shaabani, A.; Bazgir, A. Tetrahedron Lett., 2004, 45, 2575.

68. Koshkin, A. V.; Fedorova, O. A.; Lokshin, V.; Guglielmetti, R.; Hamelin, J.; Boullet, F. T. Synth. Commun., 2004, 34, 315.

\section{Short biographical pieces and Photographs}

\section{Prof. Dr. E. H. El Ashry}

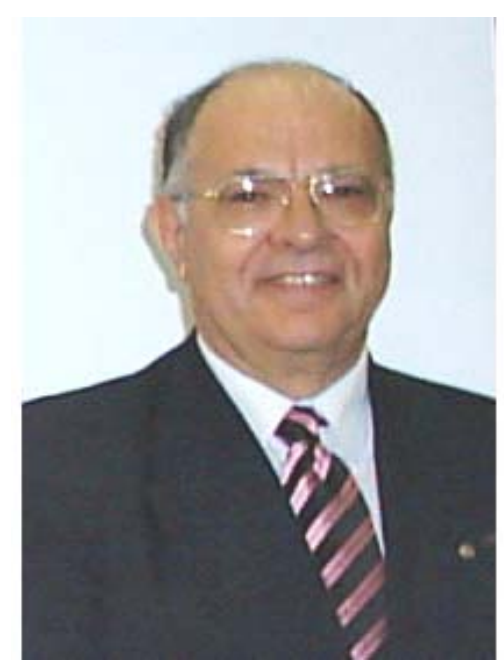

El Sayed H. El Ashry Studied chemistry at Alexandria university (BSc 1963, MSc 1966, PhD 1969 and DSc 1997). He was awarded the Alexander von Humboldt and Fullbright fellowships. He has been a visiting professor at Tokyo Institute of Technology, Ohio State University, Michigan Technological University, New York State University, Darmstadt Institute of Organic Chemistry, UmAlqura University and Konstant University. He has given lectures at various universities, institutes, companies and conferences around the world. He is currently a Professor of Organic Chemistry at Alexandria University after being the head of the department for the last four years. He has supervised more than $70 \mathrm{MSc}$ and $\mathrm{PhD}$ students and published about 300 publications and review articles in highly renowned journals in the field of carbohydrates and nucleosides, a major area of research in the series 'Heterocycles from Carbohydrate Precursors' and author of a book on 'Synthesis of Naturally Occurring Nitrogen Heterocycles from Carbohydrates' 2005. He also edits various international journals. He has received many awards of recognition and distinction: in particular 'Excellence' and '1st class Ribbon of Science and Arts' awards from the President of Egypt. 


\section{Ahmed Abdel Halim Kassem}

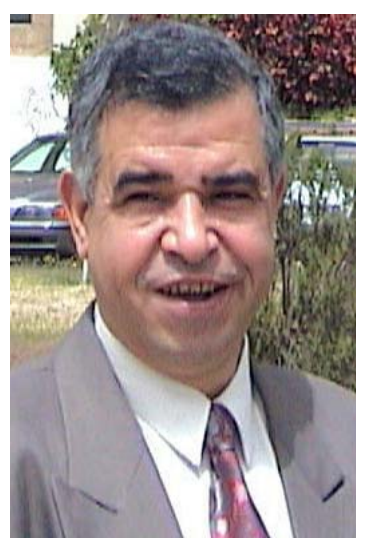

Ahmed Abdel Halim Kassem, B.Sc Egypt (1971), M.Sc Alexandria university (1976), Ph.D.TH-Merseburg, Germany (1983). Lecturer at Faculty of Science, Alexandria University, Egypt (1983-1986); Algeria University, Algeria (1986-1988). Assistance Professor at Arab Beirut University, Lebanon (1990 - 1994). Professor of Organic Chemistry at Chemistry department, Faculty of Science, Alexandria University, Egypt (1997-now). Executed Manager of Central Lab., Faculty of Science-Alexandria University-Egypt (2000-2003). Professor of organic chemistry at Chemistry department, Faculty of Science, King Khaled University, Kingdom of Saudi Arabia (2005 - Now). The major research interests are devoted to explore novel approaches for synthetic methodologies in organic chemistry and the synthesis of heterocyclic compounds. One of the main goals is the synthetic potential of monomers as starting materials for the synthesis of new co-polymers. In this respect the scope of the reactions of hydrazones and hydrazides has been explored. These polymers could be degraded and/or modified into functionalized co-polymers with various potential applications. 